\title{
The Characterization of Alpha-Subunit of Glycoprotein Hormone Produced by Undifferentiated Carcinoma
}

\author{
RYUICHIRO NISHIMURA ${ }^{1}$, TAMOTSU HAMAMOTO ${ }^{1}$, \\ NORIHIKO MORIMOTO², MITSURU OZAWA ${ }^{2}$, \\ YOSHIHIKO ASHITAKA ${ }^{1}$ AND SHIMPEI TOJO ${ }^{1}$ \\ ${ }^{1}$ Department of Obstetrics and Gynecology, Kobe University, School \\ of Medicine, Kobe 650, and ${ }^{2}$ Department of Obstetrics and \\ Gynecology, Osaka National Hospital, Osaka, Japan
}

\begin{abstract}
The glycoprotein hormone $\alpha$-subunit was extracted and purified from the urine of a patient with undifferentiated carcinoma producing isolated $\alpha$-subunit. Its final specific immunoactivity was 0.92 (mg $\alpha$-subunit/mg protein). The $\alpha$-subunit exhibited virtually identical immunoantigenecity to hCG- $\alpha$ antiserum with standard hCG- $\alpha$. The molecular weight of the $\alpha$-subunit determined by gel chromatography on Sephadex G-100 was greater than that of standard hCG- $\alpha$ dissociated by urea in vitro. By SDS disc electrophresis, however, the $\alpha$-subunit moved faster than hCG- $\alpha$ separated by mercaptoethanol reduction. The amino acid composition of the $\alpha$-subunit was quite similar to that of standard hCG- $\alpha$. In the isoelectric focusing, the major components of the $\alpha$-subunit from undifferentiated carcinoma and the $\alpha$-subunit from urine of normal pregnant women (third trimester) were distributed over the range from $\mathrm{pH} 3.5$ to 6.0 , while standard hCG- $\alpha$ was distributed in the fractions ranging from $\mathrm{pH} 6.0$ to 8.0. The result of a combination study in vitro indicated that both $\alpha$-subunits from undifferentiated carcinoma and from urine of normal pregnant women did not actively combine with hCG- $\beta$.

These results suggest that the $\alpha$-subunit secreted by undifferentiated carcinoma is virtually identical with standard hCG- $\alpha$ as the protein moiety but differs in regard to carbohydrate moiety, and also suggest that the excess of $\alpha$-subunit, which is not associated with $\beta$-subunit, may have undergone some intracellular modification, and consequently, the electric charge of the freely secreted $\alpha$-subunit changes and it no longer has the ability to combine with the $\beta$-subunit.
\end{abstract}

In addition to the eutopic synthesis and secretion of free subunits of glycoprotein hormones (Franchimont and Reuter, 1972; Laburthe et al., 1973; Vaitukaitis et al., 1976; Nishimura et al., 1979), ectopic production has been demonstrated in vivo (Weintraub and Rosen, 1973; Rosen and Weintraub, 1974) and in vitro (Tashjian et al., 1973; Chou et al., 1976; Lieblich et al., 1976). Pioneering studies on the characterization of ectopically produced $\alpha$-subunits have been reported by

Received June 16, 1981 the group of Weintraub (Weintraub et al., 1975), who extracted and purified $\alpha$-subunit from in vivo material to permit the amino acid analyses.

In placenta, hCG is likely synthesized via the association of $\alpha$ - and $\beta$ - subunits which are synthesized from two different messenger RNAs (Boime et al., 1978). Therefore, to know the characteristics of free $\alpha$-subunit is worthwhile in investigating the biosynthesis of glycoprotein hormones.

In the present study, we extracted and purified $\alpha$-subunit from urine of a patient with 
undifferentiated carcinoma producing large amounts of isolated $\alpha$-subunit, and compared its characteristics with standard hCG- $\alpha$ separated from hCG in vitro and $\alpha$-subunit from urine of normal pregnant women.

\section{Materials and Methods}

\section{Case report}

A 32-year-old para 2 Japanese woman was admitted to Osaka National Hospital in September 1977 because of gradual enlargement of a left femoral tumor, which was resected in December 1977. A chest X-ray showed multiple round shadows eight months after the initial treatment. In July 1979, we were consulted concerning her amenorrhea of three months duration, and noted a positive pregnancy test. Further examination revealed the ectopic production of immunoreactive hCG- $\alpha$. The lung lesions were identified with the femoral tumor by autopsy, and diagnosed histologically as undifferentiated carcinoma. The localization of hCG- $\alpha$ was detected by immunohistological study.

Extraction and purification of $\alpha$-subunit from the urine of a patient with undifferentiated carcinoma

Extraction of urine

Urine of the patient was extracted by the standard kaolin-acetone method which had been developed as an extraction method for urinary hCG (Borth et al., 1961).

All steps of extraction and purification were carried out at $4^{\circ} \mathrm{C}$. Eluates from the column were monitored for protein content by measuring absorbance at 280 $\mathrm{nm}$ with an Hitachi 124 spectrophotometer and assayed by homologous hCG- $\alpha$ radioimmunoassay (Ashitaka et al., 1974). Protein determinations for specific immunoactivity of $\alpha$-subunit were made by the method by Lowry et al., (1951).

Chromatography on DEAE-cellulose

The lyophilized powder was dissolved in $50 \mathrm{ml}$ of $0.005 \mathrm{M}$ Tris- $\mathrm{HCl}$ buffer, $\mathrm{pH}$ 8.0. This solution was applied to a column $(2 \times 30 \mathrm{~cm})$ on DEAE-cellulose (Brown, Lot No. MOK 8299) equilibrated with a $0.005 \mathrm{M}$ Tris- $\mathrm{HCl}$ buffer, $\mathrm{pH}$ 8.0. The elution was performed by a linear gradient of $\mathrm{NaCl}$ concentration, from $0-0.3 \mathrm{M}$, in $500 \mathrm{ml}$ of the same buffer. Five $\mathrm{ml}$ fractions were collected at a flow rate of $15 \mathrm{ml} /$ hour with a ISCO fraction collector.

Gel chromatography on Sephadex G-100

The major peak from DEAE-cellulose chromatography was passed over a Sephadex G-100 column $(2.8 \times 96 \mathrm{~cm})$ in $0.05 \mathrm{M}$ sodium phosphate buffer, $\mathrm{pH}$ 7.4. Three $\mathrm{ml}$ fractions were collected at a flow rate of $10 \mathrm{ml} /$ hour. All fractions under the peak of the absorbance and the immunoactivity of hCG- $\alpha$ were pooled, dialyzed extensively against distilled water and lyophilized.

Extraction and partial purification of $\alpha$-subunit from urine of normal pregnant women

$\alpha$-subunit was extracted from 501 of urine of normal pregnant women (third trimester) using the kaolineacetone method. Extracted material was subjected to gel chromatography on Sephadex G-100 in the same conditions as described for the purification of $\alpha$-subunit from urine of the patient.

Elution profile of $\alpha$-subunit from undifferentiated carcinoma on Sephadex $G-100$

${ }^{125}$ I-labeled $\alpha$-subunit from undifferentiated carcinoma was gel-filtrated on a $1.5 \times 90 \mathrm{~cm}$ Sephadex G-100 column. The column was calibrated with blue dextran, ${ }^{125} \mathrm{I}-\mathrm{hCG}$ and ${ }^{125} \mathrm{I}-\mathrm{hCG}-\alpha$. A ISCO fraction collector was used to collect $2.5 \mathrm{ml}$ fractions at $4^{\circ} \mathrm{C}$ at a flow rate of $12 \mathrm{ml} /$ hour.

\section{SDS disc electrophoresis}

Sodium dodecyl sulfate gel electrophoresis was performed in $7.5 \%$ polyacrylamide gel as described by Weber and Osborn (1969). The samples were dissolved in $0.02 \mathrm{M}$ phosphate buffer, $\mathrm{pH} 7.2$, containing $1 \% \mathrm{SDS}$, $2 \% 2$-mercaptoethanol, $0.05 \%$ bromophenol blue and heated at $100^{\circ} \mathrm{C}$ for two minutes before the electrophoretic run. For the determination of molecular weight by electrophoresis the standard molecular marker $(\mathrm{BDH}$, monomer of lysozym $=14,300)$ was applied under the same conditions.

\section{Amino acid analysis of $\alpha$-subunit from undifferentiated} carcinoma

Approximately $1 \mathrm{mg}$ of the $\alpha$-subunit was hydrolyzed with $6 \mathrm{~N} \mathrm{HCl}$ in a sealed tube at $110^{\circ} \mathrm{C}$ for 12 hours. After the removal of acid, the hydrolysate was analyzed by amino acid analyzer (JLC-6AH, JEOL). Tryptophan was not determined.

\section{Isoelectric focusing}

A column apparatus (Kato Co. Ltd., Japan) of $110 \mathrm{ml}$ capacity was used for this study. Approximately $2 \mu \mathrm{g}$ of samples were introduced into the sucrose gradient from 0 to $50 \%$. The mean concentration of ampholine (LKB) was $2 \%$. The column was refrigerated by circulating cold ethanol using a refrigerated circulating bath (Neslab, Model RTE 5). Isoelectric focusing was carried out for 12 hours at 400 volts, followed by 40 hours at 750 volts by a power supply (MS). Fractions $(1.5 \mathrm{ml})$ were then collected with a microfractionator (Gilson), and the $\mathrm{pH}$ of these fractions was immediately measured.

\section{Combination of alpha- and beta-subunits}

The ability of $\alpha$-subunit from undifferentiated carcinoma to combine hCG- $\beta$ subunit was determined by hCG-RIA. The recombination of standard hCG- $\alpha$ and hCG- $\beta$, separated by urea in vitro, was also 
studied as a control. The methods of combination study and calculation of the per cent of theoretical combination at time course were performed as described by Weintraub et al. (1977).

Fifteen $\mu \mathrm{g}$ of the $\alpha$ subunit and standard hCG- $\alpha$ were individually incubated with $23 \mu \mathrm{g}$ of hCG- $\beta$ according to molecular weight. The incubation was carried out at $4^{\circ} \mathrm{C}$ and $27^{\circ} \mathrm{C}$ in $100 \mu 1$ of $0.01 \mathrm{M}$ sodium phosphate, $\mathrm{pH} 7.4$, in plastic tubes $(5 \times 20 \mathrm{~mm})$ sealed with parafilm. Five $\mu \mathrm{l}$ aliquots were removed at zero time and varing time, diluted in $2 \mathrm{ml}$ of cold $0.05 \mathrm{M}$ sodium phosphate, $\mathrm{pH} 7.4$, containing $0.05 \% \mathrm{BSA}$ and stored at $-80^{\circ} \mathrm{C}$ until assay.

\section{Results}

\section{Extraction and Purification}

Table 1 shows the results of extraction and purification of $\alpha$-subunit from urine of the patient with undifferentiated carcinoma. Although the kaolin-acetone standard method had been developed as an effective extraction method for urinary hCG, $\alpha$-subunit could be also extracted from urine virtually by the same procedure. As the starting material was urine, 0.92 of the final specific immunoactivity could be attained.

Chromatography on DEAE-cellulose. (Fig. 1) Most of the immunoactivity was adsorbed with a DEAE-cellulose column and eluted as a broad large peak at conductivity ranging from 2 to 7 mmhos.

Gel chromatography on Sephadex G-100. (Fig. 2) Although two major peaks were observed by absorbance at $280 \mathrm{~nm}$, the immunoactivity of the $\alpha$-subunit was determined only in the preceding peak. This fraction containing high immunoactivity of $\alpha$-subunit was collected, dialyzed against distilled water and lyophilized.

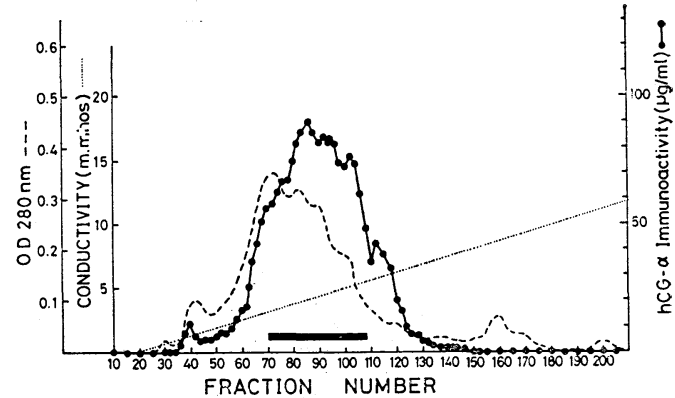

Fig. 1. Purification of $\alpha$-subunit from undifferentiated carcinoma by chromatography on DEAE-cellulose. The lyophilized powder was dissolved in $50 \mathrm{ml}$ of $0.005 \mathrm{M}$ Tris- $\mathrm{HCl}$ buffer, $\mathrm{pH} 8.0$ and applied to a DEAE-cellulose column $(2 \times 30 \mathrm{~cm})$ equilibrated with the same buffer. The elution was performed by linear gradient of $\mathrm{NaCl}$ concentration, from $0-0.3 \mathrm{M}$, in $500 \mathrm{ml} 0.005 \mathrm{M}$ Tris- $\mathrm{HCl}, \mathrm{pH} 8.0$. Five $\mathrm{ml}$ fractions were collected with a flow rate of $15 \mathrm{ml} /$ hour.

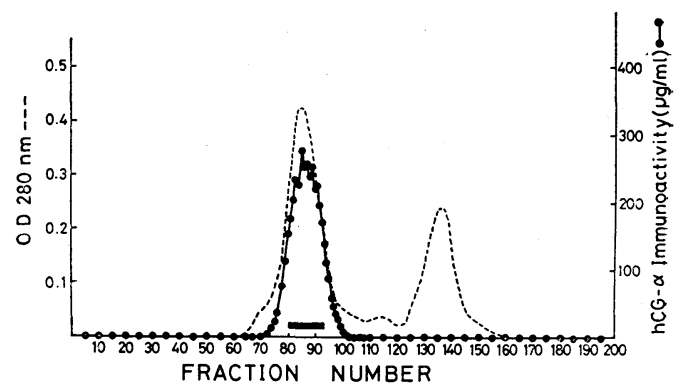

Fig. 2. Purification of $\alpha$-subunit from undifferentiated carcinoma by gel chromatography on Sephadex G-100. The major peak from DEAE-cellulose chromatography was applied to a Sephadex G-100 column $(2.8 \times 96 \mathrm{~cm})$ in $0.05 \mathrm{M}$ sodium phosphate buffer, $\mathrm{pH}$ 7.4. Three $\mathrm{ml}$ fractions were collected with a flow rate of $10 \mathrm{ml} /$ hour.

Table 1. Extraction and purification of $\alpha$-subunit from urine of patient with undifferentiated carcinoma

\begin{tabular}{lcccc}
\hline \hline & $\begin{array}{c}\text { Total Protein } \\
(\mathrm{mg})\end{array}$ & $\begin{array}{c}\text { Total Alpha } \\
(\mathrm{mg})\end{array}$ & $\begin{array}{c}\text { Specific Activity } \\
(\mathrm{mg} \text { alpha/mg protein })\end{array}$ & $\begin{array}{c}\text { Recovery } \\
(\%)\end{array}$ \\
\hline URINE & 518 & 72 & 0.14 & 100 \\
KAOLINE-ACETONE & 123 & 34 & 0.28 & 47 \\
DEAE-C & 31 & 18 & 0.58 & 25 \\
SEPHADEX G-100 & 12 & 11 & 0.92 & 15 \\
\hline
\end{tabular}




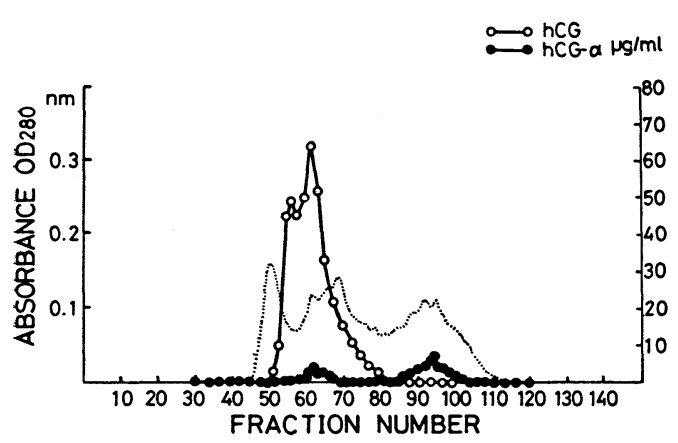

Fig. 3. Partial purification of $\alpha$-subunit from urine of normal pregnant women by gel chromatography on Sephadex G-100 in the same conditions as described for the purification of $\alpha$-subunit from urine of the patient.

Fig. 3 shows the results of gel chromatography of the extracts from urine of normal pregnant women on Sephadex G-100. Although three major peaks were observed by absorbance at $280 \mathrm{~nm}$, the immunoactivity was determined in both second and third peaks. The immunoactivity of the second peak was ascertained to be due to the crossactivity of large amounts of hCG. The fractions under the peak of hCG- $\alpha$ immunoactivity were collected, dialyzed against distilled water and lyophilized. The specific immunoactivity of this fraction was $0.26(\mathrm{mg}$ $\alpha$-subunit/mg protein). This partially purified $\alpha$-subunit was subjected to isoelectric focusing and a combination study.

\section{Elution Profiles on Sephadex G-100}

Fig. 4 depicts the elution profiles of ${ }^{125} \mathrm{I}-$ $\alpha$-subunit from undifferentiated carcinoma, ${ }^{125} \mathrm{I}$-hCG and ${ }^{125} \mathrm{I}$-hCG- $\alpha$ on a Sephadex G100 column. Ve/Vo of $\alpha$-subunit, hCG and hCG- $\alpha$ were $1.48,1.27$ and 1.71 , respectively.

\section{Immunoactivity in $h C G-\alpha$ radioimmunoassay}

Fig. 5 shows the dose response line of a purified $\alpha$-subunit from undifferentiated carcinoma in the homologous hCG- $\alpha$ RIA. The $\alpha$-subunit exhibited virtually identical immunoantigenecity against hCG- $\alpha$ antiserum with

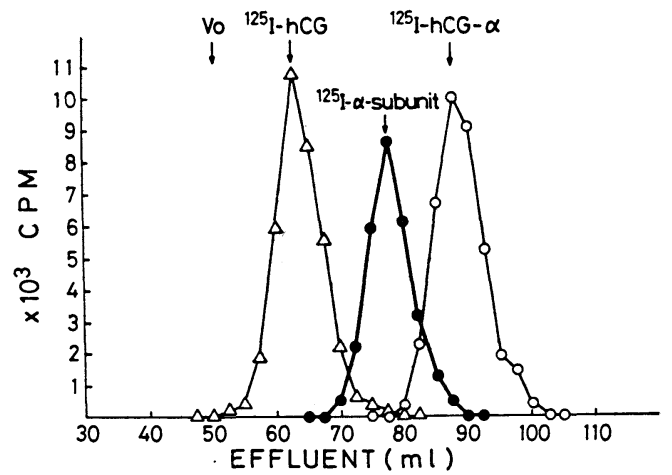

Fig. 4. Elution profiles of iodinated $\alpha$-subunit from undifferentiated carcinoma, standard hCG and hCG$\alpha$ on Sephadex G-100 column $(1.5 \times 90 \mathrm{~cm})$. Ve/Vo of $\alpha$-subunit $=1.48, \mathrm{hCG}=1.27$, hCG- $\alpha-1.71$

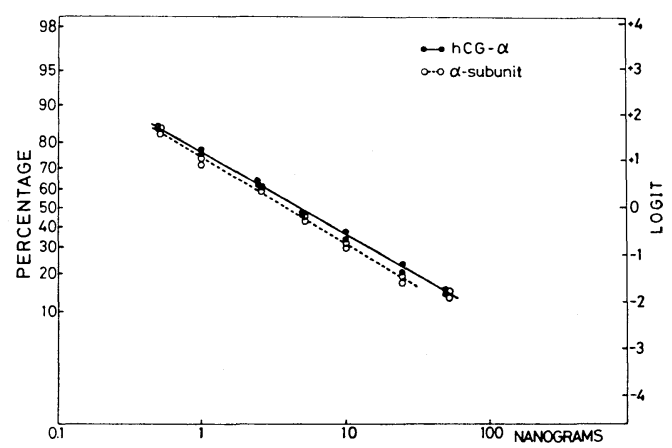

Fig. 5. The dose response line of purified $\alpha$-subunit from undifferentiated carcinoma in the homologous hCG- $\alpha$ RIA

that of standard hCG- $\alpha$.

\section{SDS disc electrophoresis}

Fig. 6 shows the results obtained following SDS disc electrophoresis of a purified $\alpha$ subunit from undifferentiated carcinoma and hCG (KOBE) after mercaptoethanol reduction. hCG was separated into two different migrating bands (Fig. 6, gel 2), whereas $\alpha$ subunit from undifferentiated carcinoma appeared as a single band (Fig. 6, gel 1). Molecular weights estimated from their mobilities showed that the faster and slower moving bands of hCG were about 19,000 and 28,000 


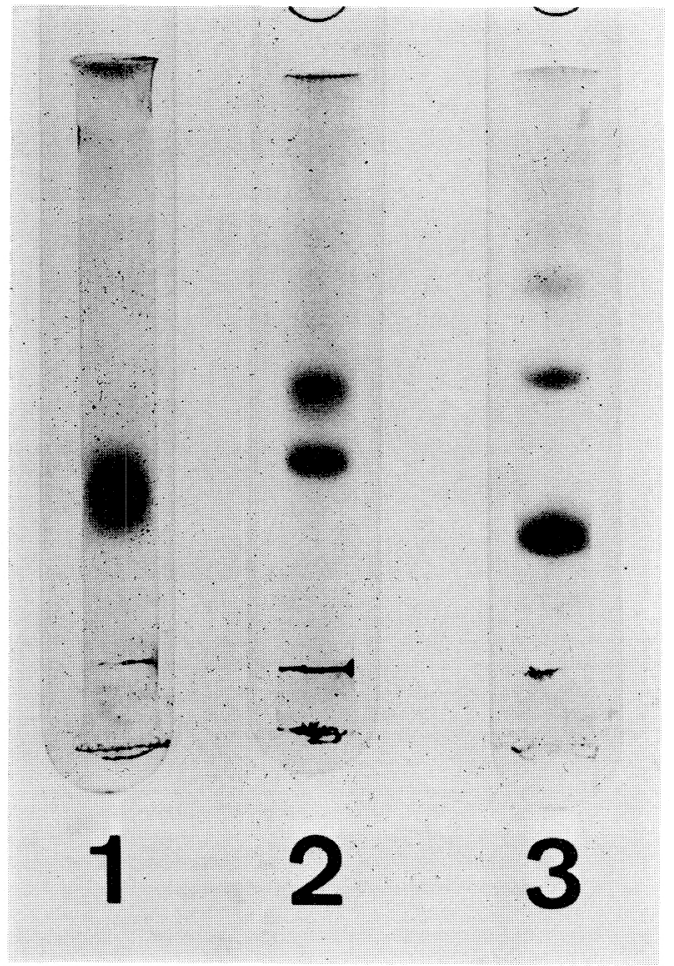

Fig. 6. SDS disc electrophoresis of $\alpha$-subunit from undifferentiated carcinoma (gel 1), hCG (gel 2) and standard molecular markers (gel 3)

respectively, and that of the $\alpha$-subunit was about 18,000 (Fig. 7).

\section{Amino acid analysis}

The results of amino acid compositions of an $\alpha$-subunit from undifferentiated carcinoma and the average of various glycoprotein hormone $\alpha$-subunits by literature analyses quoted from Weintraub et al. (1975) are listed in Table 2. There is considerable similarity in their amino acid compositions. The aspartic acid, serine, glutamic acid and glycine content in the $\alpha$-subunit was slightly higher than the literature analyses of standard $\alpha$-subunits, but the half-cystine and methionine content was lower conversely.

\section{Isoelectric focusing}

Fig. 8 depicts the isoelectric focusing pat-

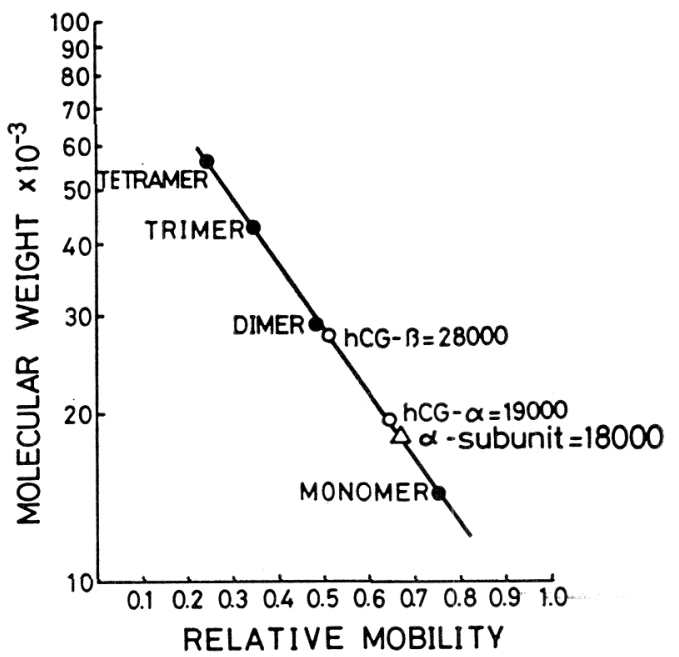

Fig. 7. Molecular weight of $\alpha$-subunit from undifferentiated carcinoma estimated by SDS disc electrophoresis. Mobilities were expressed as percentage of that of bromophenol blue used as reference.

Table 2. Amino acid analysis of $\alpha$-subunit from undifferentiated carcinoma compared to literature analyses of various human $\alpha$ $\alpha$-subunits

\begin{tabular}{lcc}
\hline \hline \multicolumn{1}{c}{ AMINO ACID* } & $\begin{array}{c}\alpha \text {-sub- } \\
\text { unit** }\end{array}$ & $\begin{array}{c}\text { human } \\
\alpha \text {-sub- } \\
\text { units*** }\end{array}$ \\
\hline Lysine & 6.2 & 6.0 \\
Histidine & 3.2 & 3.0 \\
Arginine & 3.6 & 3.6 \\
Aspartic acid & 7.5 & 6.7 \\
Threonine & 8.5 & 8.6 \\
Serine & 9.2 & 8.3 \\
Glutamic acid & 11.4 & 10.2 \\
Proline & 7.9 & 7.7 \\
Glycine & 6.7 & 5.4 \\
Alanine & 5.7 & 5.2 \\
Half-cystine & 6.9 & 9.4 \\
Valine & 7.6 & 7.5 \\
Methionine & 1.9 & 3.1 \\
Isoleucine & 1.7 & 2.1 \\
Leucine & 4.3 & 4.9 \\
Tyrosine & 3.2 & 4.0 \\
Phenylalanine & 4.5 & 4.3 \\
\hline
\end{tabular}

* expressed as moles/mole $\alpha$-subunit

** $\alpha$-subunit from undifferentiated carcinoma

*** Average of various $\alpha$-subunits quoted from Weintraub et al. (1975)

Tryptophan was not examined. 


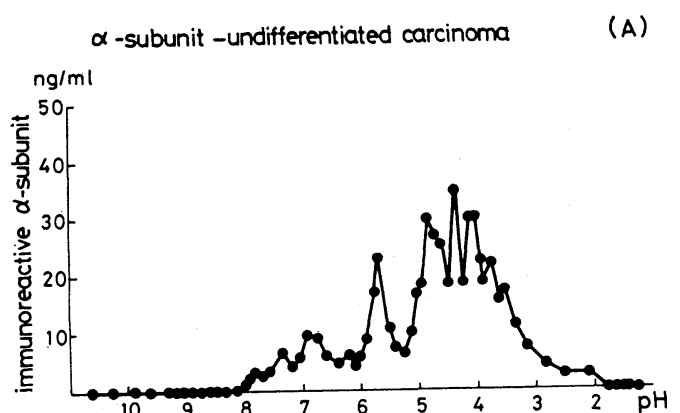

$\alpha$-subunit-normal pregnancy
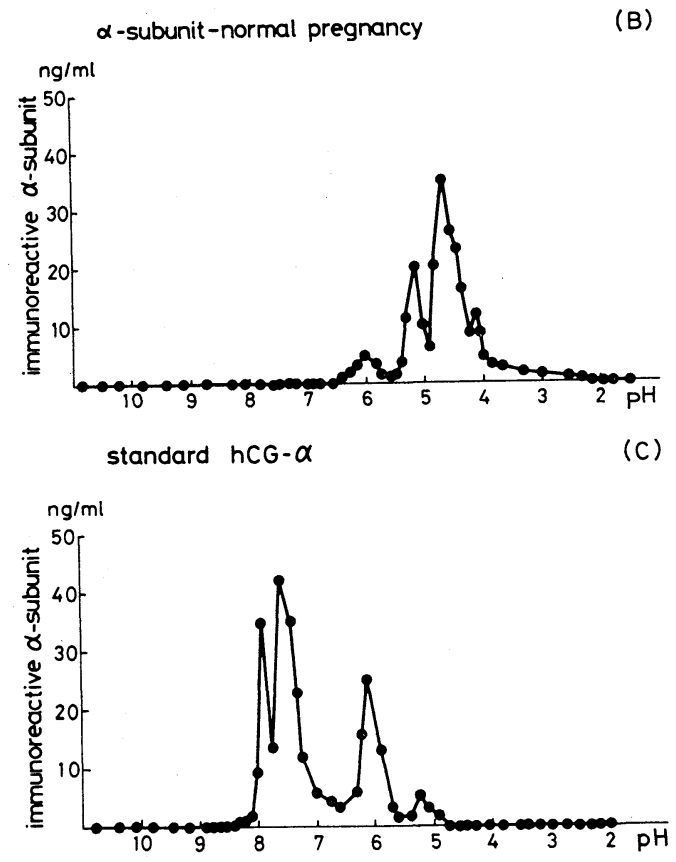

Fig. 8. The isoeleciric focusing patterns of $\alpha$-subunit from undifferentiated carcinoma (panel A), $\alpha$-subunit from urine of normal pregnant women (panel B) and standard hCG- $\alpha$ (panel C)

terns of $\alpha$-subunit from undifferentiated carcinoma (panel A), an $\alpha$-subunit from urine of normal pregnant women (panel B) and standard hCG- $\alpha$ (panel C). The major components of tumor derived $\alpha$-subunit and $\alpha$-subunit from urine of normal pregnant women were distributed over the $\mathrm{pH}$ range from 3.5 to 6.0 , whereas standard hCG- $\alpha$ was distributed in the fractions ranging from $\mathrm{pH} 6.0$ to 8.0 .

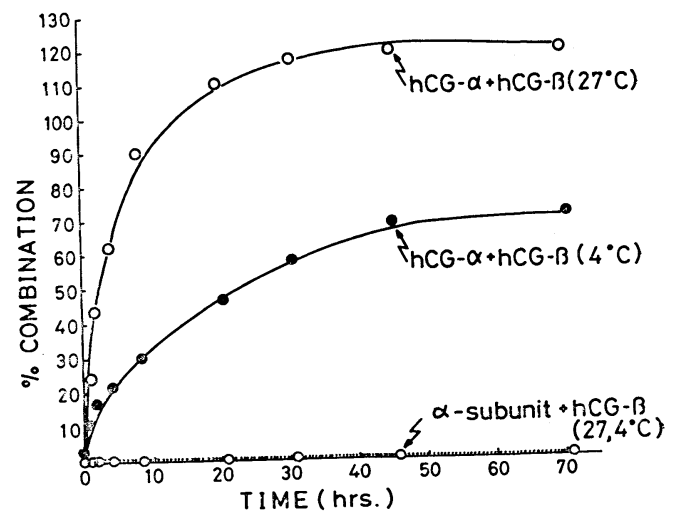

Fig. 9. Percent combination of $\alpha$-subunit from undifferentiated carcinoma and standard hCG- $\alpha$ with $\mathrm{hCG}-\beta$, as measured by hCG RIA

Combination of alpha- and beta- subunits (Fig. 9)

While the recombination between hCG- $\alpha$ and $\mathrm{hCG}-\beta$, which were separated from $\mathrm{hCG}$ by urea in vitro, increased with the time course at $4^{\circ} \mathrm{C}$ and $27^{\circ} \mathrm{C}$, the $\alpha$-subunit from undifferentiated carcinoma showed scarcely any combining activity with hCG- $\beta$ at either temperature. The assay value of the samples from the incubation tube of the $\alpha$-subunits and hCG- $\beta$ was $258 \pm 16 \mathrm{ng} /$ tube at each point of the incubation in hCG-RIA. This value practically corresponded to the crossreaction $(0.7 \%)$ of the $\alpha$-subunit plus hCG- $\beta$ for hCGRIA.

\section{Discussion}

An $\alpha$-subunit could be extracted and purified from urine of the patient with undifferentiated carcinoma. This tumor was. ascertained immunohistochemically to be an isolated $\alpha$-subunit producing tumor, and both immunoreactive $\mathrm{hCG}$ and free hCG- $\beta$ were undetectable in urine and serum of the patient.

Ectopic syntheses of subunits of glycoprotein hormones have been demonstrated in many nontrophoblastic tumors and tumor- 
derived cell lines (Weintraub and Rosen, 1973; Tashjian et al., 1973; Rosen and Weintraub, 1974; et al., 1976). Weintraub et al. (1975) extracted and highly purified $\alpha$-subunit (A.L.$\alpha, 1.84$ of specific activity) from gastric carinoid tumor tissue, and analyzed its amino acid composition. From the present results of the amino acid analysis of $\alpha$-subunit from undifferentiated carcinoma, there was considerable similarity between tumor derived $\alpha$ subunit and standard $\alpha$-subunit compositions from the literature analyses. However, Weintraub et al. (1975) reported that the amino acid composition of A.L.- $\alpha$ showed certain differences from standard, especially high glycine content. Benveniste et al. (1979) also pointed out the size heterogeneity of JEG- $\alpha$ (choriocarcinoma cell origin) and suggested the possibility that minor heterogeneity existed in its protein moiety. On the other hand, Ruddon et al. (1980) have demonstrated that subunits secreted by JAG cells (choriocarcinoma cell origin) are heterogenous and appear to be a mixture of glycoproteins with simple high-mannose and complex sialic acid-containing oligosaccharides. In the present study, since $\alpha$-subunit from undifferentiated carcinoma exhibited similar properties to standard hCG- $\alpha$ in regard to the parallel dose response and dose inhibition in homologous $\mathrm{hCG}-\alpha$ radioimmunoassay system, it was considered that little difference affecting the immunoactivity may exist between tumor derived $\alpha$-subunit and standard hCG- $\alpha$. This problem should be elucidated by the study of the amino acid sequence of the $\alpha$-subunit.

It has been demonstrated that the various ectopically produced $\alpha$-subunits have apparent larger molecular weights in gel exclusion chromatography. Also in the present study, the molecular weight of an $\alpha$-subunit from an undifferentiated carcinoma determined by gel chromatography on Sephadex G-100 was larger than that of standard hCG- $\alpha$. By SDS disc electrophoresis, however, the molecular weight of $\alpha$-subunit from undifferentiated carcinoma was smaller than that of $\mathrm{hCG}-\alpha$ separated by mercaptoethanol reduction. Weintraub et al. (1975) have already reported such a discrepancy in molecular weight estimation of $\alpha$-subunit (A.L.- $\alpha$ ) between gel chromatography and by SDS disc electrophoresis, and suggested this is attributable to the possibility that the $\alpha$-subunit might be binding more SDS than the standard $\alpha$-subunit.

In the results of the isoelectrocic fusing, the major components of $\alpha$-subunit from undifferentiated carcinoma were observed in the fractions ranging from $\mathrm{pH} 3.5$ to 6.0. This isoelectric focusing pattern was similar to that of partially purified $\alpha$-subunit from the urine of normal pregnant women, but quite different from that of standard hCG- $\alpha$ which ranged from $\mathrm{pH} 6.0$ to 8.0. Benveniste et al. (1979) showed that the great majority of JEG- $\alpha$ was dissolved in a peak pI of 4.8 which was virtually absent in standard hCG- $\alpha$. The electric charge of glycoprotein was considered to be affected by various factors, such as the differences in amino acid and carbohydrate compositions and conformation. It is probable that the tumor derived from the $\alpha$-subunit differs from standard $\mathrm{hCG}-\alpha$ in regard to carbohydrate moiety, since the protein moiety of the $\alpha$-subunit is considered to be virtually identical with that of standard hCG- $\alpha$.

The results of the combination studies involving $\alpha$ - and $\beta$-subunits indicate that $\alpha$ subunit from undifferentiated carcinoma does not actively combine with standard hCG- $\beta$. Although similar findings (Benveniste et al., 1979; Weintraub et al., 1977) have been shown in the various $\alpha$-subunits, only A.L. $-\alpha$ showed a small but significant degree of combination in both RIA and RRA. By the preliminary study, the partially purified $\alpha$-subunit from urine of normal pregnant women was not significantly active in combining with standard hCG- $\beta$ (data not shown). Therefore, the nature of hCG- $\alpha$ obtained by the dissociation of hCG may be dissimilar to that of the urinary $\alpha$-subunit, and freely secreted $\alpha$ subunit might no longer have the ability to combine with hCG- $\beta$. We suppose that A.L.- $\alpha$ 
has the ability to combine with the $\beta$-subunit because it originates from tumor tissue.

HCG may be synthesize via the association of $\alpha$ - and $\beta$-subunits which are synthesized from two different messenger RNAs (Boime et al., 1978), and hCG- $\beta$ may be a ratelimiting factor of hCG production in the placenta (Franchimont and Reuter, 1972; Chatterjee and Munro, 1977). Hence we speculate that the excess of $\alpha$-subunit, which has not associated with $\beta$-subunit, may have undergone some intracellular modification of its chemical structure, and consequently, the freely secreted $\alpha$-subunit electric charge changes and has no longer the activity to combine with the $\beta$-subunit.

We are now also studying the chemical properties and the combination of free $\alpha$ subunit in placental tissue.

\section{Acknowledgment}

This work was supported in part by Grants for Scientific Research (No. 00548285 in 1980, and 56490278 and No. 56770726 in 1981) from the Ministry of Education, Science and Culture of Japan.

\section{References}

Ashitaka, Y., Nishimura, R., Endo, Y. and S. Tojo (1974). Subunits of human chorionic gonadotropin and their radioimmunoassays. Endocrinol. Japan. 21, 429-435.

Benveniste, R., Conway, M. C., Puett, D. and D. Rabinowitz (1979). Heterogeneity of the human chorionic gonadotropin $\alpha$-subunit secreted by cultured choriocarcinoma (JEG) cells. J. clin. Endocrinol. Metab. 48, 85-91.

Benveniste, R., Lindner, J., Puett, D. and D. Rabin (1979). Human chorionic gonadotropin $\alpha$-subunit from cultured choriocarcinoma (JEG) cells: Comparison of the subunit secreted free with that prepared from secreted human chorionic gonadotropin. Endocrinology 105, 581-587.

Boime, I., Landefeld, T., McQueen, S. and McWilliams, D. (1978). The biosynthesis of chorionic gonadotropin and placental lactogen in first- and thirdtrimester human placenta. In: Structure and Function of the Gonadotropins (K. W. McKerns ed.), Plenum Press, New York, pp. 235-257.
Borth, R., Lunnenfeld, B. and A. Menzi (1961). Comparison of Kaolin-acetone methods. In: Human Pituitary Gonadotropins (A. Albert ed.), Springfield, Ill.: Charles C. Thomas. pp. 13-16.

Chatterjee, M. and H. N. Munro (1977). Structure and biosynthesis of human placental peptide. Vitam. Horm. 35, 149-208.

Chou, J. Y., Weintraub, B. D., Rosen, S. W., Whang Peng, J., Sussan, H. H., Haughom, J. R. and J. C. Robinson (1976). Synthesis of alpha subunit of human chorionic gonadotropin b0 presumptive HeLa cells. In Vitro 12, 589-594.

Franchimont, P. and A. Reuter (1972). Evidence of alpha and beta subunits of hCG in serum and urine of pregnant women. In Protein and Polypeptide Hormones (M. Margoulies and F. Greenwood ed.), Excerpta Medica, Amsterdam, pp. 381-387.

Laburthe, M. C., Dolais, J. R. and G. E. Rosselin (1973). Evidence for circulating $\alpha$ subunits of pituitary gonadotropins in plasma. J. Clin. Endcrinol. 37, 156-159.

Lieblich, J. M., Weintraub, B. D., Rosen, S. W., Chou, J. Y. and J. C. Robinson (1976). HeLa cells secrete $\alpha$ subunit of glycoprotein tropic hormones. Nature, 260, 530-532.

Lowry, O. H., Rosenbrough, N. J., Farr, A. L. and R. J. Randall (1951). Protein measurement with the folin phenol reagent. J. Biol. Chem. 193, 265275.

Nishimura, R., Ashitaka, Y. and S. Tojo (1979). The clinical evaluation of simultaneous measurements of human chorionic gonadotropin (hCG) and its alphasubunit in sera of patients with trophoblastic diseases. Endocrinol. Japan. 26, 575-583.

Rosen, S. W. and B. D. Weintraub (1974). Ectopic production of the isolated alpha subunit of the glycohormones: a quantitative marker in certain cases of cancer. N. Engl. J. Med. 290. 1441-1447.

Ruddon, R. W., Hanson, C. A., Bryan, A. H. and C. Anderson (1980). Synthesis, processing and secretion of human chorionic gonadotropin subunits by cultured human cell. In: Chorionic Gonadotropin (S. J. Segal ed.), Plenum Press, New York, pp. 295315.

Tashjian, A. H., Jr., Weintraub, B. D., Barowsky, N. J., Tabson, A. S. and S. W. Rosen (1973). Subunits of human chorionic gonadotropin: unbalanced synthesis and secretion by clonal cell strains derived from a bronchogenic carcinoma. Proc. Natl. Acad. Sci. U.S.A. 70, 1419-1422.

Vaitukaitis, J. L., Ross, G. T., Braunstein, G. D. and P. L. Rayford (1976). Gonadotropins and their subunits: basic and clinical studies. Recent Prog. Horm. Res. 32, 289-331.

Weber, K. and M. Osborn (1969). The reliability of molecular weight determinations by dodecyl sulfatepolyacrylamide gel electrophoresis. J. Biol. Chem. 244, 4406-4412.

Weintraub, B. D. and S. W. Rosen (1973). Ectopic 
production of the isolated beta subunit of human chorionic gonadotropin. J. Clin. Invest. 52, 31353142.

Weintraub, B. D., Krauth, G., Rosen, S. W. and A. S. Rabson (1975). Differences between purified ectopic and normal alpha subunits of human glycoprotein hormones. J. Clin. Invest. 56, 1043-1052.

Weintraub, B. D., Stannard, B. S., and S. W. Rosen (1977). Combination of ectopic and standard human glycoprotein hormone alpha with beta subunits: discordance of immunologic and receptor-binding activity. Endocrinology 101, 225-235. 